\title{
Coordination Between Lead and Oxydiacetic Acid
}

\author{
Göran Svensson, ${ }^{*}$ Solveig Olson and Jörgen Albertsson
}

Department of Inorganic Chemistry, Chalmers University of Technology, S-412 96 Göteborg, Sweden

\section{Dedicated to Professor Lennart Eberson on the occasion of his 65 th birthday}

\begin{abstract}
Svensson, G. Olson, S. and Albertsson, J., 1998. Coordination Between Lead and Oxydiacetic Acid. Acta Chem. Scand. 52: 868 872. (C) Acta Chemica Scandinavica 1998.

In tetralead(II) trisoxydiacetatedinitrate-water(1/1) there are three crystallographically independent lead atoms which are seven-, eight- and nine-coordinated, respectively, by oxydiacetate, water and nitrate oxygen atoms. For the sevenand eight-coordinated lead atoms, the position of the lone pair can be predicted from the coordination geometry, with lead-oxygen distances in the range $2.464(13)-2.890(13) \AA$. The lone pair of the nine-coordinated lead atom is inactive, with $\mathrm{Pb}-\mathrm{O}$ distances in the range 2.593 (14)-2.769(14) $\AA$. The coordination polyhedon for the seven-, eight- and nine-coordinated lead atoms is described as part of a cubeoctahedron, a rectangular antiprism and a monocapped rectangular antiprism, respectively. The oxydiacetate ions are almost planar. The lead atoms are connected by nitrate and oxydiacetate to form a threedimensional network.
\end{abstract}

The structure determination of the title compound is part of a general study of interactions between p-metals and small ligands of the type $\mathrm{O}_{2} \mathrm{C}-\mathrm{CH}_{2}-\mathrm{X}-\mathrm{CH}_{2}-\mathrm{CO}_{2}$, where $\mathrm{X}$ is nitrogen, oxygen or sulfur. This type of ligand can be mono-, bi- or tridentate, and can also form bridges between metal atoms. The title compound was synthesized in order to study the coordination between $\mathrm{Pb}^{\mathrm{II}}$ and the potential tridentate ligand oxydiacetic acid. The coordination to $\mathrm{Pb}^{\mathrm{II}}$ is of special interest because of the variation in the observed coordination numbers. By using a narrow-gap ligand the $6 \mathrm{~s}^{2}$ lone pair is more likely to affect the geometry of the polyhedron around $\mathrm{Pb}^{\mathrm{II}}$. Several seven-, eight- and nine-coordinated $\mathrm{Pb}^{\mathrm{II}}$ complexes with stereochemically active lone pairs are known from the literature. Two examples with O-ligands are $\mathrm{Pb}^{\mathrm{II}}$ malonate ${ }^{1}$ and $\mathrm{Pb}^{\mathrm{II}}$ oxalate, ${ }^{2}$ which are eightand seven-coordinated, respectively. Sulfur-containing ligands such as, e.g., dialkyldithiophosphinates also form complexes with active lone pairs. One example is (diethyldithiophosphinato)lead(II), where six S atoms coordinate to lead in a pentagonal bipyramid with one of the equatorial positions occupied by a lone pair. ${ }^{3}$

\section{Experimental}

Colorless crystals of the title compound were prepared by mixing aqueous solutions of $\mathrm{Pb}\left(\mathrm{NO}_{3}\right)_{2}$ and oxydiacetic acid (molar ratio $1 / 1$ ). Transparent crystals, suit-

\footnotetext{
* To whom correspondence should be addressed.
}

able for single crystal diffraction, were grown from this acid solution ( $\mathrm{pH} 1.1)$ by slow evaporation at room temperature.

Crystal data pertinent to the intensity data collection, structure solution and least-squares refinement are given in Table 1. Three intensity control reflections, measured every hour of X-ray exposure, varied within $\pm 2 \%$. Data were corrected for Lorentz, polarization and absorption effects (numerical integration, using Xtal3.4 ${ }^{4}$ ). The crystal structure was solved by direct methods and subsequent $\Delta \rho$-maps (SHELXS-86 ${ }^{5}$ ). The molar ratio between $\mathrm{Pb}$ and oxydiacetic acid was found to be $4 / 3$, not $1 / 1$ as expected, since one ligand is replaced by two nitrate groups. One $\mathrm{Pb}$, one oxydiacetate and the nitrate group are in general positions, one $\mathrm{Pb}$ and the water oxygen in a mirror plane, and one $\mathrm{Pb}$ and one oxydiacetate ion on a twofold axis. The structure was refined by full-matrix least-squares (SHELXL-93 ${ }^{6}$ ) minimizing $\Sigma w\left(\left|F_{\mathrm{o}}\right|^{2}-\left|F_{\mathrm{c}}\right|^{2}\right)^{2}$. The $\mathrm{H}$ atoms of the $\mathrm{CH}_{2}$ groups were placed in calculated positions and refined riding on the parent atoms and using a common isotropic displacement parameter. Anisotropic displacement parameters were used for $\mathrm{Pb}, \mathrm{N}$ and $\mathrm{O}$ atoms, while isotropic displacement parameters were used for $\mathrm{C}$ atoms. The final $\Delta \rho$-maps showed remaining electron density in the vicinity of the $\mathrm{Pb}$ atoms. The magnitudes of the final displacement parameters for the nitrate and water molecules indicate disorder which could not be resolved. The large remaining electron density close to the $\mathrm{Pb}$ atoms and the 
Table 1. Crystal data and refinement parameters.

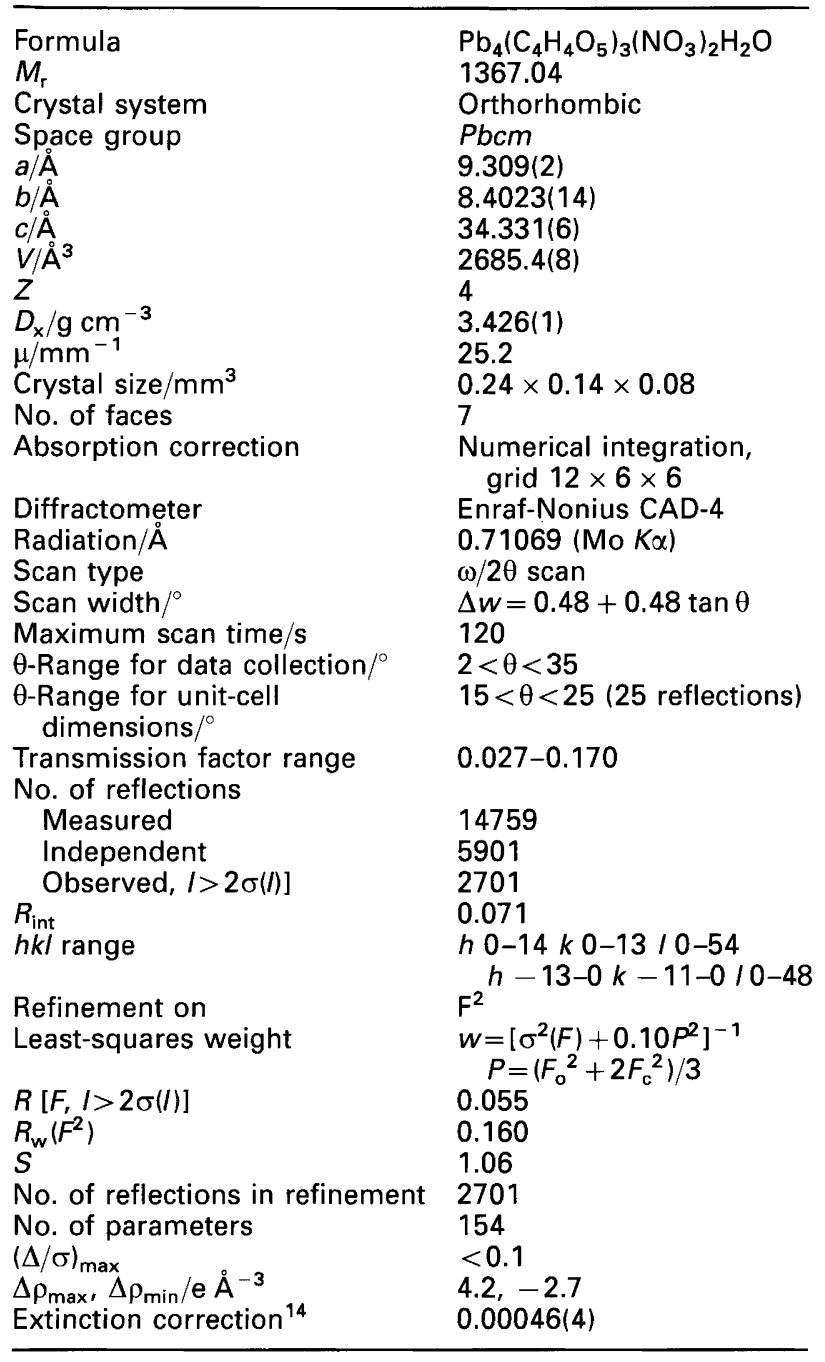

Table 2. Fractional atomic coordinates and equivalent isotropic displacement parameters (in $\AA^{2}$ )

\begin{tabular}{lllll}
\hline Atom & $x / a$ & $y / b$ & $z / c$ & $U_{\text {eq }}{ }^{a}$ \\
\hline $\mathrm{Pb} 1$ & $0.06630(13)$ & $0.07622(13)$ & $3 / 4$ & $0.0360(3)$ \\
$\mathrm{Pb} 2$ & $0.32015(8)$ & $0.07376(8)$ & $0.61852(2)$ & $0.0310(2)$ \\
$\mathrm{Pb} 3$ & $0.43388(11)$ & $3 / 4$ & $1 / 2$ & $0.0248(2)$ \\
$\mathrm{O} 1$ & $0.2060(15)$ & $0.3492(16)$ & $0.6153(4)$ & $0.037(3)$ \\
$\mathrm{O} 2$ & $0.0396(16)$ & $0.3139(17)$ & $0.7086(4)$ & $0.043(4)$ \\
$\mathrm{O} 3$ & $0.1495(17)$ & $0.1418(16)$ & $0.6704(4)$ & $0.041(4)$ \\
$\mathrm{O} 4$ & $0.3633(19)$ & $0.2375(15)$ & $0.5592(4)$ & $0.044(4)$ \\
$\mathrm{O} 5$ & $0.385(2)$ & $0.4696(16)$ & $0.5285(4)$ & $0.049(4)$ \\
$\mathrm{O} 6$ & $0.136(2)$ & $-1 / 4$ & $1 / 2$ & $0.054(6)$ \\
$\mathrm{O} 7$ & $0.1013(18)$ & $-0.0073(18)$ & $0.5823(5)$ & $0.049(4)$ \\
$\mathrm{O} 8$ & $0.2905(16)$ & $-0.1338(17)$ & $0.5579(4)$ & $0.042(4)$ \\
$\mathrm{O} 9$ & $-0.194(3)$ & $0.135(5)$ & $3 / 4$ & $0.103(12)$ \\
$\mathrm{O} 10$ & $0.304(4)$ & $-0.177(4)$ & $0.6754(11)$ & $0.21(2)$ \\
$\mathrm{O} 11$ & $0.479(3)$ & $-0.198(3)$ & $0.6425(10)$ & $0.125(11)$ \\
$\mathrm{O} 12$ & $0.453(3)$ & $-0.355(4)$ & $0.6895(9)$ & $0.142(12)$ \\
$\mathrm{N} 1$ & $0.410(3)$ & $-0.246(2)$ & $0.6695(8)$ & $0.063(6)$ \\
$\mathrm{C} 1$ & $0.141(2)$ & $0.4121(19)$ & $0.6498(5)$ & $0.027(3)$ \\
$\mathrm{C} 2$ & $0.108(2)$ & $0.2818(19)$ & $0.6776(5)$ & $0.025(3)$ \\
$\mathrm{C} 3$ & $0.256(2)$ & $0.467(2)$ & $0.5878(5)$ & $0.032(4)$ \\
$\mathrm{C} 4$ & $0.339(2)$ & $0.386(2)$ & $0.5566(6)$ & $0.032(4)$ \\
$\mathrm{C} 5$ & $0.0564(16)$ & $-0.1806(16)$ & $0.5315(4)$ & $0.042(5)$ \\
$\mathrm{C} 6$ & $0.1588(16)$ & $-0.1026(16)$ & $0.5588(4)$ & $0.029(4)$ \\
\hline
\end{tabular}

${ }^{a} U_{\text {eq }}=8 / 3 \pi^{2}\left[U_{11}\left(a a^{*}\right)+U_{22}\left(b b^{*}\right)+U_{33}\left(c c^{*}\right)\right]$

shape of the displacement parameters, elongated perpendicularly to the plane of the oxydiacetate groups, for the ligands also indicate some kind of disorder which could not be resolved. Diffraction data were therefore collected for three different crystals from two separate preparations. Refinement of these data sets resulted in a similar model with the same problems. Atomic scattering factors and anomalous dispersion factors were taken from Ref. 7.

Final atomic coordinates and equivalent displacement parameters are given in Table 2 and selected geometrical parameters in Table 3. Displacement ellipsoid plots

Table 3. Selected bond distances (in $\AA$ ) and angles (in ${ }^{\circ}$ ) with e.s.d.s in parentheses.

\begin{tabular}{|c|c|c|c|c|c|}
\hline $\begin{array}{l}\mathrm{Pb} 1-\mathrm{O} 2 \\
\mathrm{~Pb} 1-\mathrm{O} 9 \\
\mathrm{~Pb} 1-\mathrm{O} 233 \\
\mathrm{~Pb} 1-\mathrm{O} 3 \\
\mathrm{~Pb} 3-\mathrm{O} 5 \\
\mathrm{~Pb} 3-08 \text { 6 } \\
\mathrm{Pb} 3-05 \text { 5 } \\
\mathrm{Pb} 3-06 \text { 7 } \\
\mathrm{Pb} 3-04 \_5\end{array}$ & $\begin{array}{l}\left(\_2\right) \\
(44) \\
(44) \\
(8) \\
(-7) \\
(99) \\
(99)\end{array}$ & $\begin{array}{l}2.464(13) \\
2.51(3) \\
2.798(14) \\
2.890(13) \\
2.592(13) \\
2.593(14) \\
2.673(15) \\
2.77(2) \\
2.769(14)\end{array}$ & & $\begin{array}{l}\mathrm{Pb} 2-07 \\
\mathrm{~Pb} 2-\mathrm{O} 3 \\
\mathrm{~Pb} 2-04 \\
\mathrm{~Pb} 2-01 \\
\mathrm{~Pb} 2-08 \\
\mathrm{~Pb} 2-011-5 \\
\mathrm{~Pb} 2-010 \\
\mathrm{~Pb} 2-011\end{array}$ & $\begin{array}{l}2.487(17) \\
2.467(13) \\
2.493(12) \\
2.549(13) \\
2.732(4) \\
2.78(2) \\
2.86(2) \\
2.87(2)\end{array}$ \\
\hline $\begin{array}{l}\mathrm{C} 1-01 \\
\mathrm{C} 1-\mathrm{C} 2 \\
\mathrm{C} 2-\mathrm{O} 2 \\
\mathrm{C} 2-03 \\
\mathrm{~N} 1-010\end{array}$ & $\begin{array}{l}1.44(2) \\
1.48(2) \\
1.26(2) \\
1.26(2) \\
1.19(3)\end{array}$ & $\begin{array}{l}\text { O1-C3 } \\
\text { C3-C4 } \\
\text { C4-O4 } \\
\text { C4-O5 } \\
\text { N1-O11 }\end{array}$ & $\begin{array}{l}1.44(2) \\
1.48(7) \\
1.28(2) \\
1.28(2) \\
1.22(3)\end{array}$ & $\begin{array}{l}\text { C5-O6 } \\
\text { C5-C6 } \\
\text { C6-O7 } \\
\text { C6-08 } \\
\text { N1-012 }\end{array}$ & $\begin{array}{l}1.44(2) \\
1.49(2) \\
1.26(2) \\
1.24(2) \\
1.23(3)\end{array}$ \\
\hline $\begin{array}{l}\mathrm{C} 1-O 1-\mathrm{C} 3 \\
\mathrm{O} 1-\mathrm{C} 1-\mathrm{C} 2 \\
\mathrm{C} 1-\mathrm{C} 2-\mathrm{O} 2 \\
\mathrm{C} 1-\mathrm{C} 2-\mathrm{O} 3 \\
\mathrm{O} 2-\mathrm{C} 2-\mathrm{O} 3\end{array}$ & $\begin{array}{l}115.3(13) \\
110.6(13) \\
119.0(15) \\
119.8(15) \\
121.2(16)\end{array}$ & $\begin{array}{l}\mathrm{C} 5-\mathrm{O} 6-\mathrm{C} 5-10 \\
\mathrm{O} 1-\mathrm{C} 3-\mathrm{C} 4 \\
\mathrm{C} 3-\mathrm{C} 4-\mathrm{O} 4 \\
\mathrm{C} 3-\mathrm{C} 4-\mathrm{O} 5 \\
\mathrm{O} 4-\mathrm{C} 4-\mathrm{O} 5\end{array}$ & $\begin{array}{l}117.5(18) \\
109.1(15) \\
119.5(7) \\
118.7(16) \\
121.7(18)\end{array}$ & $\begin{array}{l}\mathrm{O} 6-\mathrm{C} 5-\mathrm{C} 6 \\
\mathrm{C} 5-\mathrm{C} 6-\mathrm{O} 7 \\
\mathrm{C} 5-\mathrm{C} 6-08 \\
\mathrm{O} 7-\mathrm{C} 6-\mathrm{O} 8\end{array}$ & $\begin{array}{l}108.7(9) \\
113.9(10) \\
120.9(9) \\
125.1(16)\end{array}$ \\
\hline
\end{tabular}

Symmetry transformations used:
(2) $x, y, 3 / 2-z ;$ (3) $-x,-1 / 2+y, z ;$ (4) $-x,-1 / 2+y, 3 / 2-z$
(5) $1-x, 1 / 2+y, z$
(6) $x, 1 / 2-y, 1-z$
(7) $x, 1+y, z$;

(8) $x, 3 / 2-y_{1} 1-z_{;}$(9) $1-x, 1-y_{1} 1-z ;$ (10) $x,-1 / 2-y_{1}-z+1$. 
$\left(\right.$ ORTEP- $\left.3^{8}\right)$ of the $\mathrm{Pb}$ coordination are shown in Figs. 1a-1c. The geometry around the lead atoms are shown in Figs. $2 \mathrm{a}-2 \mathrm{c}$ and a packing stereo-diagram in Fig. 3.

A list of observed and calculated structure factors, anisotropic displacement parameters and hydrogen atom parameters is available from one of the authors (G.S.)

\section{Description of the structure}

In the title compound the $\mathrm{Pb}$ atoms are coordinated by oxydiacetate, water and nitrate $\mathrm{O}$ atoms. The three crystallographically independent $\mathrm{Pb}$ atoms are seven-, eight- and nine-coordinated, respectively. To the best of our knowledge this is the first compound where seven-, eight- and nine-coordinated lead have been found in the same structure.

$\mathrm{Pbl}$ is seven-coordinated by four oxydiacetate ions and the water molecule, with $\mathrm{Pbl}$ and the water oxygen in a mirror plane. Two of the planar organic ligands are bidentate and two are unidentate (Fig. 1a). The seventh position in the coordination shell is occupied by the water molecule $\mathrm{O} 9$. The range of the $\mathrm{Pb1}-\mathrm{O}$ distances is 2.464(13)-2.890(13) $\AA$ with a Pb1-O9 (water) distance

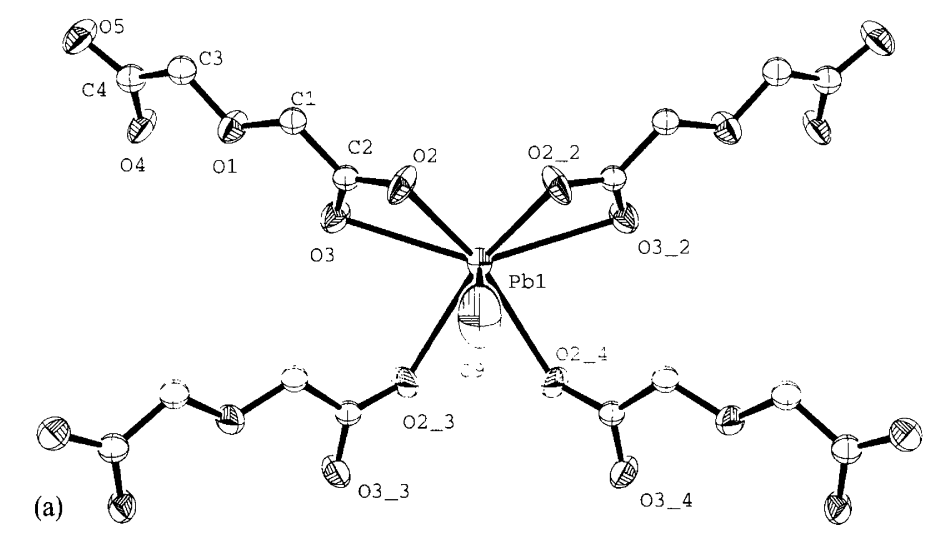
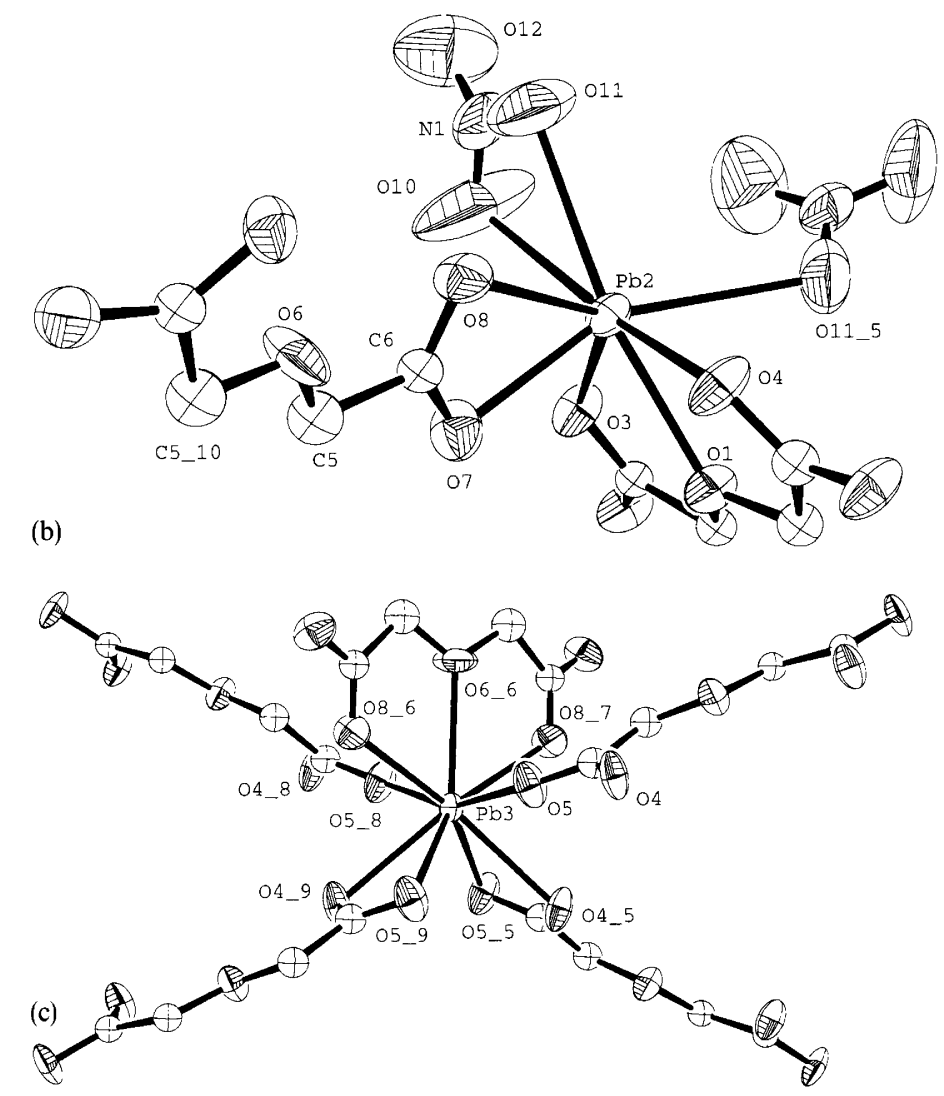

Fig. 1. The coordination of the lead atoms in tristetralead(II) oxydiacetatedinitrate-water (1/1). Lead is seven-coordinated in (a), eight-coordinated in (b) and nine-coordinated in (c). Symmetry related oxygen atoms are generated by the symmetry operations given in Table 3 . Thermal ellipsoids are scaled to include $50 \%$ probability. 

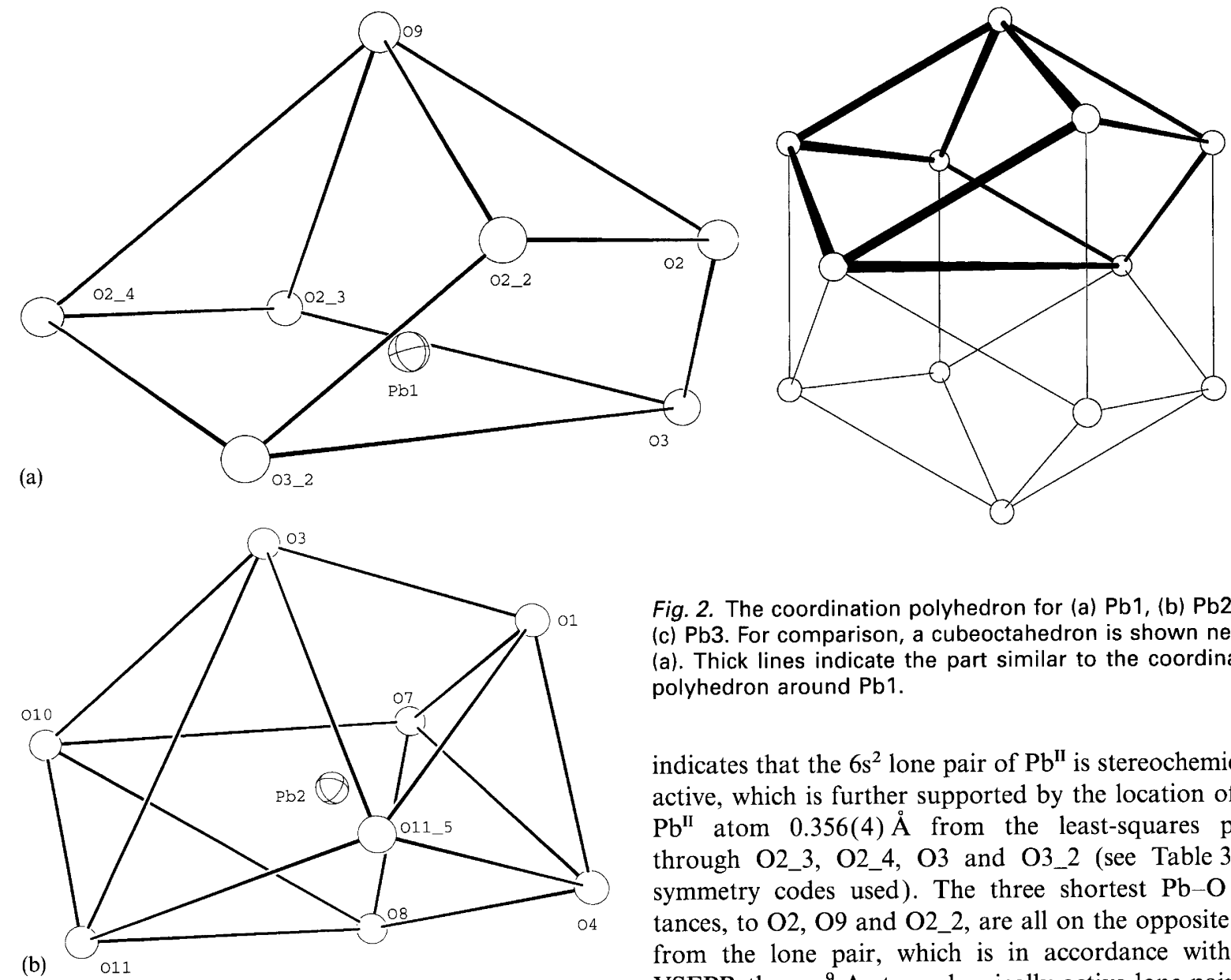

(b)

Fig. 2. The coordination polyhedron for (a) $\mathrm{Pb} 1,(\mathrm{~b}) \mathrm{Pb} 2$ and (c) Pb3. For comparison, a cubeoctahedron is shown next to (a). Thick lines indicate the part similar to the coordination polyhedron around $\mathrm{Pb} 1$.

indicates that the $6 \mathrm{~s}^{2}$ lone pair of $\mathrm{Pb}$ il is stereochemically active, which is further supported by the location of the $\mathrm{Pb}^{\mathrm{II}}$ atom 0.356(4) $\AA$ from the least-squares plane through O2_3, O2_4, O3 and O3_2 (see Table 3 for symmetry codes used). The three shortest $\mathrm{Pb}-\mathrm{O}$ distances, to $\mathrm{O} 2, \mathrm{O} 9$ and $\mathrm{O} 2 \_2$, are all on the opposite side from the lone pair, which is in accordance with the VSEPR theory. ${ }^{9}$ A stereochemically active lone pair has

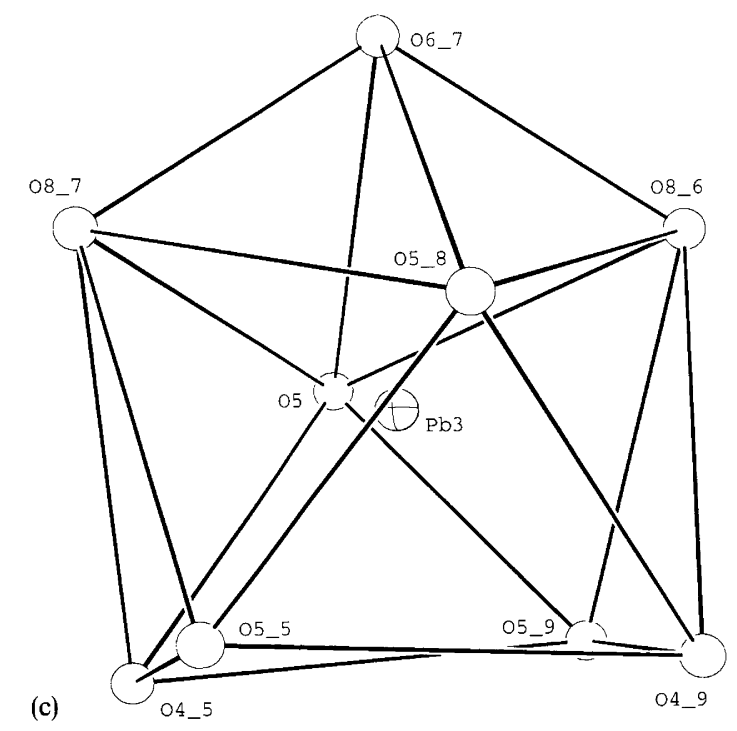
also been found in other seven-coordinated $\mathrm{Pb}^{\text {II }}$ compounds. In bis(oxamato- $O, O^{\prime}$ ) lead(II) water $(1 / 1)^{10}$ the coordination polyhedron is described as a pentagonal bipyramid with the lone-pair out of the equatorial plane. A pentagonal bipyramid was also found in lead(II)oxalate trihydrate. ${ }^{11}$ In lead(II) oxalate dihydrate ${ }^{2}$ the coordination polyhedron can be described as a distorted square antiprism with an empty vertex. The most probable direction of the lone pair is towards this vertex. The seven-coordinate geometry for lead in aquabis $\left(p\right.$-nitrosalicylato- $\left.O, O^{\prime}\right)$ lead(II) is described as highly irregular, with an empty region available for the lone pair. ${ }^{12}$

$\mathrm{Pb} 2$ is eight-coordinated and coordinates to two oxydiacetate ligands, one being tridentate and the other bidentate. The three remining sites for coordination number 8 are occupied by $\mathrm{O}$ atoms from two nitrate groups. The $\mathrm{Pb}-\mathrm{O}$ distances range from $2.467(17)$ to $2.87(2) \AA$, with the nitrate $\mathrm{O}$ atoms forming the longest bond. The coordination polyhedron is highly irregular. To accom-

of 2.51(3) $\AA$. The coordination polyhedron is shown in modate the lone-pair as a ninth vertex, it may be described as a rectangular antiprism with $\mathrm{O} 4, \mathrm{O} 8, \mathrm{O} 11$ Fig. 2a compared with a cubeoctahedron, which indicates that the polyhedron formed around $\mathrm{Pb} 1$ may be interpreted as a part of that polyhedron. As can be seen from Fig 2a, the coordination is rather one-sided, with ample space available where the lone-pair can be located. This and $011 \_5$ forming one of the rectangles and $\mathrm{O} 1, \mathrm{O} 3$, $\mathrm{O} 10$ and $\mathrm{O} 7$ the other (Fig. $2 \mathrm{~b}$ ). The stereochemically active lone-pair may then be located in the first of these faces, in this way completing a severly distorted mono- 

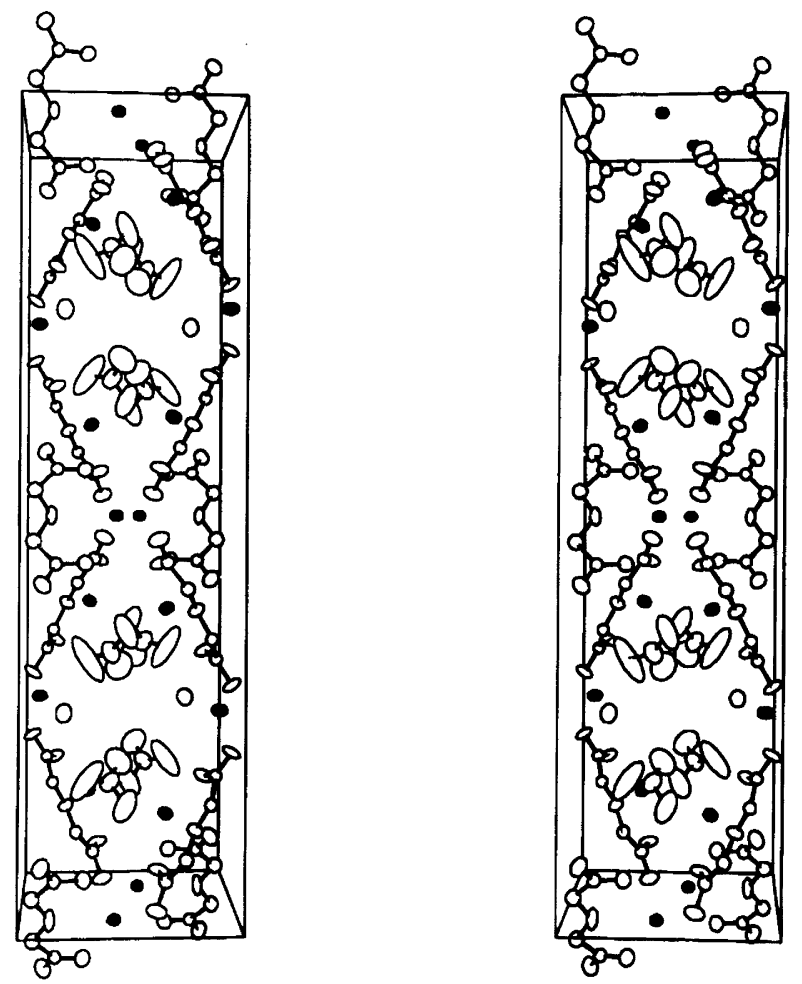

Fig. 3. Crystal packing projected along [100].

capped rectangular antiprism, which is one of the regular geometries for nine-coordination. The distance from $\mathrm{Pb} 2$ to the plane formed by $\mathrm{O} 4, \mathrm{O} 8, \mathrm{O} 11$ and $\mathrm{O} 11 \_5$ is 1.074(10) $\AA$, which is the shortest distance between Pb2 and any possible boundary plane of the polyhedron. A monocapped rectangular antiprism is also found in lead(II)malonate, ${ }^{1}$ where the lone-pair also occupies one vertex.

$\mathrm{Pb} 3$ is nine-coordinated by five oxydiacetate ligands. One acts as a tridentate ligand, two as bidentate and two as monodentate ligands (Fig. 1c). The $\mathrm{Pb}-\mathrm{O}$ distances range from $2.593(14)$ to 2.769 (14) $\AA$. The geometry of the $\mathrm{PbO}_{9}$ polyhedron can be desribed as a monocapped square antiprism, with $06 \_7$ as the capping atom (Fig. 3c), or with the alternative description as a tricapped trigonal prism, with O6_7, O4_9 and O4_5 as capping atoms. These two polyhedra are closely related, with symmetry $C_{4 \mathrm{v}}$ and $D_{3 \mathrm{~h}}$, respectively. The position of the lone pair is not obvious from the geometry of the coordination polyhedron. The high coordination number makes it less likely that the lone pair should infuence the geometry. This is also indicated by the closer range of $\mathrm{Pb}-\mathrm{O}$ distances for the nine-coordination compared to what is found for the seven- and eight-coordinated $\mathrm{Pb} 1$ and $\mathrm{Pb} 2$. In lead acetate trihydrate ${ }^{13}$ nine oxygen atoms form a monocapped square antiprism. One of the $\mathrm{Pb}-\mathrm{O}$ distances is elongated, 3.09(4) $\AA$, while the others are in the range $2.47(3)$ to $2.85(5) \AA$. The most likely position for the lone pair is, therefore, along this elongated bond.

One of the ligands $(\mathrm{O} 1-\mathrm{O} 5, \mathrm{Cl}-\mathrm{C} 4)$ coordinates to nine $\mathrm{Pb}$ atoms and the other (O6-O8, C5-C6) to seven. The carboxylate oxygen atoms interact with two $\mathrm{Pb}$ atoms each, except for $\mathrm{O} 7$, which has one interaction only. Each ether oxygen interacts with one lead atom, only. In this way a three-dimensional network is formed (Fig. 3). The oxydiacetate ligands form wave-like chains along $c$ with the $\mathrm{Pb}$ atoms, water molecules and nitrate ions in between chains.

Acknowledgment. Financial support by the Swedish Natural Science Research Council (NFR) is gratefully acknowledged.

\section{References}

1. Bench, W. \& Günter, J. R. Z. Kristallog. 178 (1987) 257.

2. Virovets, A. V., Naumov, D. Y., Boldyreva, E. V. and Podberezskaya, N. V. Acta Crystallogr., Sect. C49 (1993) 1882.

3. Svensson, G. and Albertsson, J. Acta Chem. Scand. 45 (1991) 820 .

4. Hall, S. R., King, G. S. D. and Stewart, J. M., Eds. Xtal3.4 User's Manual. University of Western Australia, Lamb, Perth 1995.

5. Sheldrick, G. M. SHELXS-86. A Program for Crystal Structure Solution. University of Göttingen, Germany 1986.

6. Sheldrick, G. M. SHELXL-93. A Program for Refinement of Crystal Structures. University of Göttingen, Germany 1993.

7. International Tables for X-Ray Crystallography, Vol. C, Kluwer Academic Publishers, Dordrecht, The Netherlands 1992.

8. Farrugia, L. J. J. Appl. Crystallogr. (1997). In press.

9. Gillespie, R. J. and Nyholm, R. S. Quart. Rev. Chem. Soc. 11 (1957) 339.

10. Skoulika, S., Michaelides, A. and Aubry, A. Acta Crystallogr., Sect. C44 (1988) 808.

11. Sheng-Hua, H., Ru-Ji, W. and Mak, T. C. W. J. Crys. Spectrosc. Res. 20 (1990) 99.

12. Tahir, M. N., Ülkü, D. and Móvsümov, E. M. Acta Crystallogr., Sect. C52 (1996) 2436.

13. Rajaram, R. K. and Rao, J. K. M. Z. Kristallogr. 160 (1982) 225 .

Received January 23, 1998. 